\title{
Abnormal uterine bleeding: a study of menstrual patterns and histopathological patterns in perimenopausal females
}

\author{
Mahima Jain*, Nilesh Gorania \\ Department of Obstetrics \& Gynecology, PDU Medical College, Rajkot, Gujarat, India
}

Received: 27 November 2014

Accepted: 19 December 2014

\section{*Correspondence:}

Dr. Mahima Jain,

E-mail: drmahimajain@yahoo.co.in

Copyright: ( $\odot$ the author(s), publisher and licensee Medip Academy. This is an open-access article distributed under the terms of the Creative Commons Attribution Non-Commercial License, which permits unrestricted non-commercial use, distribution, and reproduction in any medium, provided the original work is properly cited.

\begin{abstract}
Background: In gynecology out-patient department there is a large group of patients especially in perimenopausal age group who present with various menstrual disorders. These can be as such caused due to various etiologies, which need to be investigated as line of management is thereupon decided. This study is undertaken to know the various abnormal uterine bleeding in perimenopausal women, and their histopathological pattern.

Methods: This study is done at PDU medical college hospital, Rajkot, Gujarat which is a tertiary care centre. A retrospective analysis of 268 cases clinically presenting with abnormal uterine bleeding is done. They are further posted for dilatation \& curettage after thorough investigation to rule out other pathologies. The endometrial samplings from the D\& C material are collected and sent for histopathological assessment. The data is recorded and further analysed. Women between 40-55 years age group are included in this study. Women with diagnosed pelvic pathology, endocrinal cause and bleeding tendencies are excluded from the study.

Results: In our study almost all menstrual disorders are found, commonest being menorrhagia in $42.16 \%$. Other patterns reported are metrorrhagia in $3.35 \%$, oligomenorrhea in $14.80 \%$, polymenorrhea and polymenorrhagia in $5.22 \%$ and $5.59 \%$ cases. Post-menopausal bleeding is found in one case. The histopathological diagnoses reported in this study are proliferative and secretory phase in $26.49 \%$ and $19.77 \%$ respectively. Other endometrial hyperplasias reported are Swiss cheese in $1.86 \%$, simple cystic hyperplasia in $12.31 \%$, complex hyperplasia with or without atypia in $7 \%$ and $4.10 \%$ respectively. Malignancy is found in 2 cases.

Conclusions: From this study it is well established that endometrial sampling from D\&C material still remains the gold standard in diagnosis of various endometrial pathologies in low resource set-up. Thereby the further line of management can also be decided for a rational approach in the treatment of perimenopausal women with abnormal uterine bleeding.
\end{abstract}

Keywords: Abnormal uterine bleeding, Perimenopausal females, Histopathological diagnosis

\section{INTRODUCTION}

Abnormal uterine bleeding is the most common \& challenging problems presenting to a gynecologist. It is responsible for one-third of all out patient department cases. It can be caused by systemic diseases, endocrine disorders, drugs or due to pelvic pathology.

Histopathological examination of endometrial samples still remains the gold standard for diagnosis of endometrial pathology. The importance of endometrial biopsy or curettage is to obtain material for histopathological evaluation to aid in diagnosis and further management cannot be overemphasized especially in perimenopausal females who are at risk of developing malignancy. ${ }^{5}$

\section{Aims \& objectives}

1. To know the menstrual patterns in patients presenting with AUB in perimenopause. 
2. To evaluate the histopathological patterns in endometrial samples.

\section{Review of literature}

Perimenopause is defined as the period around menopause that spreads from 40 to 55 years of age. ${ }^{7}$

Various abnormal menstrual bleeding were defined as follows: ${ }^{9}$

Menorrhagia: cyclic bleeding at normal intervals, the bleeding is either excessive in amount $>80 \mathrm{ml}$ or duration or both.

Polymenorrhea: cyclic bleeding where the cycle is reduced to an arbitrary limit of 21 days or less and remains constant at that frequency.

If frequent cycle is associated with excessive and or prolonged bleeding it is called polymenorrhagia.

Metrorrhagia is defined as irregular, acyclic bleeding from the uterus.

Menometrrorhagia is when the bleeding is so irregular and excessive that the menses cannot be identified at all.

Oligomenorrhea is menstrual bleeding occurring more than 35 days apart and constant at that frequency.

Histological diffentiation of Endometrial Hyperplasias is as follows: ${ }^{9}$

1. Cystic hyperplasia: glands are spherically dilated and lined by columnar epithelium without any evidence of secretory activity.

2. Adenomatoous hyperplasia: glands show outpouching like fingers into the stroma. The glands are placed back to back, there is no atypical cellular changes.

3. Atypical hyperplasia: There is variation in size, shape, polarity and staining of the cellular lining of the hyperplastic epithelium.

4. Swiss cheese hyperplasia: marked hyperplasia of all the endometrial components with cystic glandular hypertrophy with marked disparity in sizes.

5. Complex adenomatous without atypia: glands closely packed, complex pattern, scanty stroma.

6. Complex adenomatous with atypia: closely packed glands, complex pattern with features of atypia and glands with increased nuclear/cytoplasmic ratio and irregular shape and size of nuclei, loss of polarity.
Dilatation and curettage is commonly used in developing countries and is the gold standard in diagnosis of endometrial hyperplasias.

\section{METHODS}

The present study was done in PDU medical college, Rajkot, a tertiary care hospital. A retrospective analysis of 268 patients clinically presenting with abnormal uterine bleeding was done.

Detailed history like age, menstrual patterns was taken. Detailed history regarding amount, duration and pattern of bleeding and other associated gynecological problems were noted. General and systemic examination of these patients done.

$\mathrm{Hb}$, RBS, Urine routine \& microscopic examination was done to rule out medical condition. And then posted for Dilatation \& curettage as day care procedure after proper counseling and consent.

Endometrial samples were obtained from D\&C material collected in $10 \%$ formalin and sent for histopathological analysis. Histopathological endometrial patterns reported were then recorded and studied.

\section{Inclusion criteria}

Women in the age group of 40 to 55 years.

\section{Exclusion criteria}

Women with pelvic pathology like fibroid, bleeding diathesis, endocrine diseases like hypothyroidism, diabetes etc., pregnancy and its related complications.

Women outside age group as included in our criteria.

Statistical analysis includes simple percentage.

\section{RESULTS}

As shown below the most common abnormal uterine bleeding is menorrhagia in $42.16 \%$. A high number of cases had continuous bleeding per vaginum in $27.61 \%$ cases (Table 1).

In our study only one case had post-menopausal bleeding. Other all types of abnormal uterine bleeding were seen in our study having varied range from $3 \%$ to $13.80 \%$. Hence there is a wide variation in the menstrual pattern in perimenopausal age group but predominated by menorrhagia (Table 1).

In our study $37.68 \%$ patients had clinically normal size uterus but were symptomatic (Table 2). 
Table 1: Distribution of various menstrual patterns.

\begin{tabular}{|ll|l|}
\hline Menstrual pattern & $\begin{array}{l}\text { Number of } \\
\text { cases }(\mathbf{n}=268)\end{array}$ & $\begin{array}{l}\text { Percentage } \\
(\%)\end{array}$ \\
\hline Menorrhagia & 113 & 42.16 \\
\hline Metrorrhagia & 9 & 3.35 \\
\hline Menometrorrhagia & 5 & 1.86 \\
\hline Oligomenorrhea & 37 & 13.80 \\
\hline Polymenorrhea & 14 & 5.22 \\
\hline Polymenorrhagia & 15 & 5.59 \\
\hline $\begin{array}{l}\text { Continuous bleeding } \\
\text { per vaginum }\end{array}$ & 74 & 27.61 \\
\hline Post-menopausal & 1 & 0.37 \\
\hline
\end{tabular}

Table 2: Distribution according to clinical assessment of uterine size.

\begin{tabular}{|lll|}
\hline Size of uterus & $\begin{array}{l}\text { Number } \\
(\mathrm{n}=\mathbf{2 8})\end{array}$ & $\begin{array}{l}\text { Percentage } \\
(\mathbf{\%})\end{array}$ \\
\hline Normal size & 101 & 37.68 \\
\hline Bulky uterus & 167 & 62.31 \\
\hline
\end{tabular}

As shown in the Table 3 the most common histopathological finding reported is proliferative and secretory ohase endometrium. But other endometrial hyperplasias such as Swiss cheese pattern, adenomatous hyperplasia, simple cystic hyperplasia were also reported in $1.86 \%$ and $12.31 \%$ cases.

The other types reported and of significance in further management of abnormal uterine bleeding in perimenopause women are scomplex hyperplasias with or without atypia in $4 \%$ and $7 \%$ cases. Thus the importance of endometrial sampling in abnormal uterine bleeding is there emphasized.

Table 3: Distribution according to histopathological diagnosis.

\begin{tabular}{|lllll|}
\hline $\begin{array}{l}\text { Histopathologic } \\
\text { pattern }\end{array}$ & $\begin{array}{l}\text { Number } \\
(\mathrm{n=268)} \\
\text { our }\end{array}$ & $\begin{array}{l}\text { Shazia } \\
\text { study }\end{array}$ & $\begin{array}{l}\text { Layla } \\
\text { et al. } \\
(\%)^{7}\end{array}$ & $\begin{array}{l}\text { S et al. } \\
(\%)^{6}\end{array}$ \\
\hline Proliferative phase & 71 & 26.49 & 33 & 15.4 \\
\hline Secretory phase & 53 & 19.77 & 26 & 16.6 \\
\hline Pseudodecidualization & 23 & 8.58 & - & - \\
\hline $\begin{array}{l}\text { Swiss cheese pattern / } \\
\text { cystic adenomatous } \\
\text { hyperplasia }\end{array}$ & 5 & 1.86 & 1 & - \\
\hline $\begin{array}{l}\text { Simple cystic } \\
\text { hyperplasia }\end{array}$ & 33 & 12.31 & 25 & 10.5 \\
\hline $\begin{array}{l}\text { Complex hyperplasia } \\
\text { without atypia }\end{array}$ & 11 & 4.10 & - & 1.8 \\
\hline $\begin{array}{l}\text { Complex hyperplasia } \\
\text { with atypia }\end{array}$ & 19 & 4.10 & - & 0.54 \\
\hline Malignancy & 2 & 0.74 & 1 & 1.5 \\
\hline Endometritis & 8 & 2.98 & 13 & 7.2 \\
\hline Irregular maturation & 35 & 13.05 & - & 11.6 \\
\hline No interpretation & 8 & 2.98 & - & 10.6 \\
\hline
\end{tabular}

Malignancy is reported in 2 patients also is of importance as the line of further surgical management in these cases can thereby be planned. Chronic endometritis is reported in $2.98 \%$ cases as incidence of pelvic inflammatory diseases is also increased these days.

Thus once again dilatation and curettage appears to be a gold standard to detect endometrial pathologies and thereby help the clinican to decide the further line of management.

\section{DISCUSSION}

Abnormal uterine bleeding is a common gynecological problem accounting for upto $20 \%$ of the visits to the gynecologists. Dilatation and curettage is a useful and cost effective method of detecting intrauterine pathologies and very few lesions escape detection.

It is commonly used in developing countries with limited resources as a standard and often the only means of assessing abnormal uterine bleeding in a cost effective manner.

Histopathological evaluation of the curettage specimen is necessary in identifying the cause of abnormal uterine bleeding. This carries special significance in the perimenopausal age group because of increased incidence of intrauterine lesions in this age group.

Menorrhagia is a common complain reported in literature between $51.9 \%$ and $53.3 \%$. Metrorrhagia seen in $18 \%$ is the second commonest clinical presentation.

Histopathological evaluation of endometrial curettage yielded various pattern ranging from physiological to pathological lesions of endometrium. The commonest was secretory endometrium $(28.9 \%)$ closely followed by proliferative endometrium $(24.9 \%)$, chronic endometritis in $6.1 \%$. Simple hyperplasia accounted for $64.8 \%$.One patient reported with post-menopausal bleeding whereas malignancy is detected in 2 cases. Premalignant endometrial lesion like complex hyperplasia with or without atypia is detected in $7.08 \%$ and $4.10 \%$.

Inadequate samples are reported when no specimen is obtained or the quality is insufficient for assessment. ${ }^{7}$

\section{CONCLUSION}

All patients having abnormal menstrual bleeding should be subjected to dilatation and curettage to rule out endometrial pathology.

Accurate analysis of endometrial sample is the key to effective therapy and rational approach to treatment of women with abnormal uterine bleeding.

Thus D\&C still remains the gold standard diagnostic investigation in low resource setting and thereby to 
improve the detection of premalignant and malignant endometrial pathologies.

Funding: No funding sources Conflict of interest: None declared

Ethical approval: The study was approved by the institutional ethics committee

\section{REFERENCES}

1. Khare R, Bansal S, Sharma P, Elhence N, Makkar N, Tyagi Y. Morphological spectrum of Endometrium in patients presenting with DUB. Peoples' J Sci Res. 2012 Jul;5(2):13-6.

2. Rajshri P. Damle, N. V. Dravid, Kishor H. Suryawanshi, Arundhati S. Gadre, Priya S. Bagale, Neelam Ahire. Clinicopathological spectrum of endometrial changes in perimenopausal and postmenopausal abnormal uterine bleeding: a 2 years study, J Clin Diagn Res. 2013 Dec;7(12):2774-6.

3. Zeeba S. Jairajpuri, S. Rana, S. Jetley. Atypical uterine bleeding - histopathological audit of endometrium: a study of 638 cases. Al Ameen J Med Sci. 2013;6(1):21-8.
4. Vaidya S, Latchey M, Vaidya S, Sharma PK, Hirachand S, Lama S, et al. Histopathological pattern of abnormal uterine bleeding in endometrial biopsies. Nepal Med Coll J. 2013;15(1):74-7.

5. Dutta DC. Abnormal menstrual bleeding. In: Dutta DC, eds. Text Book of Gynecology. 4th ed. New Delhi, India: Jaypee Brothers Medical Publishers; 2007: 175-177.

6. Layla S. Abdullah, Nabeel S. Bondagji. Histopathological pattern of endometrial sampling performed for abnormal uterine bleeding. Bahrain Med Bull. 2011 Dec;33(4):1-6.

7. Riaz S, Ibrar F, Dawood NS, Jabeen A. Endometrial pathology by endometrial curettage in menorrhagia in perimenopausal age group. J Ayul Med Coll Abbottabad. 2010;22(3):161-4.

DOI: $10.5455 / 2320-1770 . \mathrm{ijrcog} 20150221$

Cite this article as: Jain M, Gorania N. Abnormal uterine bleeding: a study of menstrual patterns and histopathological patterns in perimenopausal females. Int J Reprod Contracept Obstet Gynecol 2015;4:109-12. 